\title{
Inflammatory Bowel Disease, Ulcerative Colitis, Crohns Disease or Indeterminate Colitis? Diagnostic Challenge
}

\author{
Neeraj Nagaich ${ }^{1 *}$, Radha Sharma ${ }^{2}$ and Niranjana Nair ${ }^{3}$ \\ ${ }^{1}$ Department of Gastroenterology, India \\ ${ }^{2}$ Department of Pathology, India \\ ${ }^{3}$ JSS College of Pharmacy, India \\ *Corresponding author: Neeraj Nagaich, Fortis Escorts Hospital, India \\ Submission: 海 September 26, 2018; Published: 眥 February 04, 2019
}

Keywords: Chronic colitis; Crohn's disease; Indeterminate; Ulcerative

Abbreviations: UC: Ulcerative Colitis; CD: Crohn's Disease; IC: Indeterminate Colitis; OMGE: Organization Mondiale de Gastroenterologie; TB:

Tuberculosis; IBDU: Inflammatory Bowel Disease Unclassified; CIBD: Chronic Inflammatory Bowel Disease

\section{Introduction}

In most instances, ulcerative colitis and crohn's disease may be readily distinguished from each other pathologically, particularly when each exhibit classic histological features. However, some patients with IBD show overlapping pathological features of Ulcerative Colitis (UC) and Crohns Disease (CD), Which makes definite distinction between these two disorders difficult and often results in an interim diagnosis of 'Indeterminate Colitis' (IC). Other forms of colitis, such as microscopic colitis, diverticulitis and diversion colitis may, on occasion, also show lBD-like changes. The clinical and pathological features that aid in the distinction between these entities, and others, are covered in detail in this review.

\section{Diagnostic Criteria for IBD}

Various diagnostic classifications of IBD are available, including. Mendeloff's criteria, 24 the Lennard-Jones criteria, 25 the international multicentre scoring system of the Organization Mondiale de Gastroenterologie (OMGE), 26 and the diagnostic criteria of Japanese Research Society on IBD. 27. Modified Mendeloff criteria plus key points of the Lennard- Jones criteria, commonly used criteria, are presented here

\section{Ulcerative colitis}

A. Definite

i. History of diarrhea or rectal bleeding for 6 weeks or more with:

ii. At least one sigmoidoscopy or colonoscopy revealing one or more of the following: mucosal friability, petechial hemorrhage, diffuse inflammatory ulceration; radiological evidence of ulceration or narrowing/shortening of the colon; characteristic macroscopic and microscopic changes in a specimen obtained by surgical resection or biopsy.

B. Probable

i. A compatible sigmoidoscopy, colonoscopy, or barium enema with inadequate history;

ii. A compatible history with dubious sigmoidoscopic or colonoscopic appearance and no barium enema;

iii. An adequate history but dubious radiological findings and no sigmoidoscopy or colonoscopy report; and

iv. A characteristic macroscopic appearance of the operative specimen with an uncertain histology.

After exclusion of infectious colitis, ischemic colitis, radiation colitis, solitary rectal ulcer, findings compatible with $\mathrm{CD}$, if compatible histology is found, such as continuous mucosal inflammation without granulomas and rectal involvement with continuity of the colon, the diagnosis is regarded as 'Definite'; in the absence of histological confirmation, the diagnosis is regarded as 'Probable'.

\section{Crohn's disease}

Definite Characteristic pathological and histological findings in an operative specimen showing segmental, transmural lesions, fissuring ulcers, and non-caseating ranulomas and lymphoid aggregates in the lamina propria and submucosa.

\section{A. Probable}

i. A laparotomy report of characteristic naked-eye appearance of the bowel but no specimen for histology; 
ii. An equivocal histological report from an operative specimen with characteristic macroscopic features;

iii. A colonoscopic report compatible with $\mathrm{CD}$, and biopsy histologic features strongly suggestive of $C D$; and

iv. A radiologic examination showing chronic inflammation with obstruction or fistulae.

After exclusion of infections (particularly intestinal Tuberculosis [TB]), ischemia, radiation, lymphoma or carcinoma, if granulomas are present with at least another criteria or, in the absence of granulomas, with three of the characteristic lesions, such as skip lesions, discrete ulcers, fissuring ulcers, fistulae, strictures or aphthoid ulcers etc., a diagnosis of CD is regarded as 'definite'; if two criteria without granuloma are present, the diagnosis is regarded as 'probable'. The term 'indeterminate colitis' should be used when only the colon is involved, and the diagnosis of UC or CD is impossible based on the aforementioned criteria.

The criteria used by the Japanese Research Society on IBD are outlined as follows.

\section{Ulcerative colitis}

A. Symptoms

Continuous or repeated bloody diarrhea;

B. Endoscopy

Diffuse inflammation, loss of vascular pattern, friability (bleeding at contact), abundant mucus and

i. Granular appearance;

ii. Multiple erosions, ulcers; and

iii. Pseudopolyps, loss of haustration (lead-pipe pattern), lumen narrowing, and colonic shortening.

\section{Histology}

a) Active: inflammatory cells infiltration, crypt abscess, goblet cell depletion.

b) Remission: Crypt architectural abnormalities (distortion branching), atrophic crypts. These changes usually begin in the rectum and extend proximally in continuity. Definite diagnosis: $\mathrm{A}+$ one item of $\mathrm{B}$ and $\mathrm{C}$.

\section{Crohn's Disease}

\section{Major findings}

a) Longitudinal ulcer;

b) Cobblestone appearance;

c) Non-caseating granuloma. Minor findings;

d) Irregular-shaped ulcer or aphthoid ulcers;

e) Irregular-shaped ulcer or aphthoid in upper and lower gastrointestinal tract.

\section{Definite diagnosis}

i. C along with either $\mathrm{A}$ or $\mathrm{B}$;

ii. C and D or E.

\section{Suspect}

i. A or B, but cannot exclude ischemic colitis or ulcerative colitis;

ii. C;

iii. D or E.

The criteria are quite simple and easy to apply, but the exclusion criteria should be applied first; in particular the epidemic infectious disease should be excluded first in this region. A suggested guideline from China paid more attention to the scrutinizing and evaluation of the patients, and the exclusion criteria applied first.

\section{Architecture}

Mucosal architecture plays a major role in the pathological interpretation of IBD. Changes in architecture are the results of damage to the crypts, superficial epithelium, and lamina propria. Moreover, the intestinal architecture may revert to normal in IBD in remission or in a quiescent phase. Patients referred to qualified centers after a first acute episode often have a normal histology at the second biopsy. It is therefore useful to review the slides prepared from biopsies taken during the first acute episode. Asymptomatic patients may have abnormalities in mucosal architecture as a result of major damage, leading to defective healing with crypt loss, branching, or metaplastic changes of the Paneth cell or Pseudopyloric type. These cases, marked by alterations limited to the mucosal architecture without active inflammation, are often referred to as unclassified IBD, with further definition depending on the modality of inflammation during the active phase of disease. The appropriate timing of the biopsy is crucial in lesion detection. At disease onset, basal lymphoplasmacytosis in the lamina propria occurs over a period of 2 weeks but is, in fact, better observed during the third week [1].

\section{Biases and mimics}

Patients treated with enemas (5-ASA, butyrate) were reported to have a statistically higher percentage of normal biopsies (36\%) per patient than patients in the corresponding placebo-treated group (12\%) [2]. In up to $60 \%$ of patients with ulcerative colitis (UC), previously inflamed segments of colon convert to normal following treatment with oral anti-inflammatory agents, such as sulfasalazine or steroids. Thus, evaluation of disease "continuity" by mucosal biopsies is not useful to distinguish UC from CD in previously treated IBD patients. Some patients develop a form of UC characterized by complete endoscopic and histologic sparing of the transverse colon in the presence of left-sided proctosigmoiditis in association with either cecal or ascending colon inflammation. Patients with fulminant UC and extensive mucosal ulceration may show CD-like histological features, such as relative or complete rectal sparing, patchy ulceration, fissuring ulceration, and transmural lymphoid inflammation.

Several inflammatory disorders can mimic CD: segmental inflammation, granulomatous inflammation, ileal inflammation in UC before and after ileal pouch anal anastomosis (IPAA), and aphthoid ulcers with skip interval mucosa as in ischemic and NSAID colitis [2]. In addition, infections with Entamoeba 
histolytica, Salmonella, and Yersinia, which typically cause a right-side-predominant or segmental colitis, may mimic CD endoscopically. Superimposed infections caused by Clostridium difficile or cytomegalovirus should be considered in CD patients receiving steroids or immunosuppressive therapy, with unexpected recurrences, or with refractory illness [3].

\section{Granulomas}

Granulomas have been traditionally considered a feature of $\mathrm{CD}$; however, the emphasis given to this pattern of inflammation may be misleading. The more the histopathology is dominated by granulomas, the less reliable is the diagnosis of CD. Granulomas are formed around broken crypts, whatever the cause, be it as a reaction to the discharge of mucin deep in the intestinal wall or to penetrating intestinal luminal contents consequent to any fissuring process, including infection, UC, perfusion disorders such as vasculitis or heart surgery, etc. Due to the local environment of $\mathrm{CD}$, infection is often if not always the second component of disease activity. Up to $80 \%$ of the cases of active CD respond to antibiotic therapy [4].

\section{Slide reviewing}

In referral centres for IBD, slide reviewing for a second opinion is frequently requested by gastroenterologists. The basic questions to the pathologist are: is it IBD? Is the differential between CD and UC feasible? Frequently, the approach to the patient changes following the pathologist's opinion. The diagnosis of IBD is affected by problems in inter-observer reproducibility and by misunderstandings in communication. The most frequent source of the latter is the term "inflammation," regardless of whether it is qualified with the additional terms "chronic," "acute," or "nonspecific." If associated with symptoms of long duration, the automatic translation into chronic colitis or ileitis is common. In addition, two major normal functions are erroneously interpreted as pathological findings: inflammatory-cell trafficking inside the mucosa and reactive lymphoid hyperplasia in the lymphatic tissue (Peyer's patches) of the ileum or involving lymphoepithelial complexes in the large bowel.

As in all equilibrium settings, the features of both vary within the range of normal. Another bias comes from the general definition of chronic inflammation as a response sustained by lymphocytes and plasma cells, and acute inflammation by granulocytes. In the chronic inflammatory process of IBD, granulocytes are a constant component of disease activity. Lymphocytes and plasma cells are normally present in the gastrointestinal tract mucosa and are increased in number in acute inflammation.

\section{The biopsy-based histopathology of Crohn's Disease}

5.8.1.Stepwise approach: While CD can affect different segments of the gastrointestinal tract, the microscopic features are similar at all sites. The diagnosis of CD is based on the presence of aphthoid ulcers, fissural ulcers, sinus tracts, granulomas, transmural lymphoid hyperplasia, fibromuscular obliterations, and vascular and neural changes. However, most of these findings cannot be detected on endoscopic biopsy samples. Furthermore, the mucosal lesions can be very mild. CD may demonstrate wide overlap with
UC on mucosal biopsy examination. In addition, several types of chronic colitis may mimic the features of UC and CD. The analysis of multiple biopsies allows a correct diagnosis of IBD in $66-75 \%$ of newly diagnosed patients. Additional endoscopic and clinical data allow a final diagnosis in more than $90 \%$.

In practice, the first step in evaluating mucosal biopsies is to establish a diagnosis of colitis based on the presence of epithelial damage and inflammation. Subsequently, a possible etiology should be included in order to differentiate between IBD and other types of chronic colitis. The last step is to solve the differential diagnosis between CD and UC, which can be done by the location of the disease, the distribution of the lesions, and the presence of ileal lesions [5]. The diagnosis of IBD on endoscopic biopsies relies therefore on the detection of reproducible microscopic criteria that consist of changes in the architecture, a cellular inflammatory response, and epithelial cell alterations. Abnormalities of the mucosal architecture include an irregular/pseudovillous mucosal surface, architectural distortion of the crypts (non-parallel, variable diameter, or cystically dilated), crypt branching and shortening, and decreased crypt density.

Crypt distortion in the colon, one of the major features in the diagnosis of IBD, is usually not present in the early phase and generally takes two months to develop. The architectural alterations may be focal, discontinuous, or diffuse. The cellularity of the lamina propria changes in intensity, composition, and distribution pattern and may be diffuse or discontinuous (focal/patchy). In the diffuse pattern there is an increase in cellularity throughout the lamina propria, with basal plasmacytosis. The latter occurs in $38 \%$ of patients within two weeks following the onset of colitis and has a high predictive diagnostic value. Patchy inflammation is diagnosed when the mucosal background shows inflammation of varying intensity, while focal inflammation is defined as a small collection of inflammatory cells in an otherwise normal mucosa [6]. Sarcoidtype granulomas are traditionally considered the hallmark of CD, even if present in only $50 \%$ of the cases of small-bowel CD. In rectal biopsies of patients with $\mathrm{CD}$, the overall incidence of granulomas is $>20 \%$. They are more common in young patients (42\%) with short disease duration. Infectious diseases such as tuberculosis and yersiniosis should be considered when granulomas are seen.

Peri cryptal granulomatous inflammation is not a specific feature of CD and also can be seen in UC. A well-formed single granuloma, non-necrotizing, basally oriented, and unrelated to ruptured crypts is highly suggestive of $\mathrm{CD}$ and remains one of the most useful markers of the disease [7]. Epithelial alterations, including mucin depletion, Paneth cell metaplasia, and flattening of the superficial epithelial cells, are indicative of damage and the ensuing repair process. Disease activity in IBD is usually assessed based on infiltration by polymorphonuclear neutrophils of the surface epithelium, crypt epithelium (cryptitis), or crypt Lumina (crypt abscesses). Crypt destruction, erosions, and ulcerations are other markers of disease activity.

The presence of ileal lesions is one of the major features discriminating between CD and UC. In chronic ileitis, structural changes consist of abnormalities in villi shape and size (blunting, 
enlargement, broadening at the top, atrophy, or diffuse shortening) and in the crypts, which can become branching, shortened, atrophic or lost, and arranged in groups. The epithelial lining can be normal or show increased mucin production. Changes in the crypt epithelium include ulcer-associated cell lineage (pseudo pyloric gland metaplasia) and an increase in the number of Paneth cells displaced higher up in the crypts [8]. Aphthoid erosion is defined as a mucosal erosion occurring over lymphoid aggregates such as Peyer's patches; it is present in $>50 \%$ of CD patients but it is not specific.

Features that favor a diagnosis of $\mathrm{CD}$ are chronic active inflammatory changes in the terminal ileum, less severe disease in the distal than in the proximal colon, Aphthoid Ulcers, epithelioid granulomas unassociated with crypt rupture, segmental architectural changes with patchy inflammation and focal cryptitis in the colonic mucosa, involvement of the upper gastrointestinal tract, and the presence of normal and inflamed samples from the same areas (skip areas). In $10-20 \%$ of all CD patients, the disease involves the colorectal mucosa with a diffuse pattern of inflammation without skip lesions and closely mimicking the endoscopic and biopsy features of UC [9].

A variety of circumstances can modify the usual histological patterns such that the separation of $C D$ and UC becomes very difficult. Rectal sparing and patchy inflammation associated with focal minimal architectural alterations have been documented in biopsies from children presenting with new-onset UC, in adult patients under treatment, in patients with primary sclerosing cholangitis and IBD, and in patients presenting with severe fulminant disease. Therefore, in these conditions, the diagnosis of IBD unclassified (IBDU) has been proposed [5].

\section{Ulcerative Colitis}

Whilst UC is classically considered to involve the rectum and distal colon in a diffuse and continuous fashion, there are certain situations where UC may appear patchy or segmental. This can give the false impression of a 'skip lesion' and might suggest a diagnosis of either CD or IC, the latter especially in cases where most of the features point to a diagnosis of UC but the skip lesions are confounding. In fulminant UC, the predominant impact of the disease is in the more proximal colon, in particular the transverse colon. This may give an impression of rectal sparing a recognized feature of colonic CD. Fulminant UC is often associated with a variable intensity of inflammation throughout the colorectum, which can be confused with the characteristic skip lesions of CD [10]. Treatment by enemas can accentuate apparent sparing of the rectum and lower left colon. Both oral steroids and sulphasalazine may also cause patchiness of disease. Topical and/or systemic treatment can lead to complete histological reversal of the morphogical features of UC activity and even chronicity on biopsy [11]. So, floridly active UC treated with anti-inflammatory enemas can lead to notable amelioration of the disease in the rectum and sigmoid colon and thus apparent (relative) sparing of the distal colorectum This may encourage the pathologist to label such a case erroneously as IC.

Pathologists should be aware of any recent treatment when assessing IBD resection specimens. In paediatric practice, some discontinuous disease is a well-recognized feature of UC patients and relative rectal sparing is also a commoner feature in children with UC than in adult patients [12]. The appendix may show involvement by UC and this may be discontinuous. This was previously considered a rare phenomenon, but now is thought to be relatively common, reported to occur in up to $86 \%$ of colonic resections [13]. Originally described as a 'skip lesion' of UC, such acute mucosal appendicitis in UC may occur with the proximal colon entirely normal: it is not, per se, a rationale for a diagnosis of IC.

Similarly, a small cohort of UC patients, with left-sided disease, may demonstrate involvement of the caecum and/or proximal ascending colon, whilst the distal ascending colon and transverse colon are spared. The term 'caecal patch' is used for this occurrence, encompassing the inflammation seen in both the caecum and the proximal ascending colon [14]. Like acute mucosal appendicitis, it is entirely acceptable to see such discontinuous pathology in UC and it, too, does not necessitate the alternative diagnosis of IC. Finally, backwash ileitis in UC must not be mistaken for terminal ileal involvement by $\mathrm{CD}$ or lead to the alternative diagnosis of IC because there are features 'atypical' for UC. Backwash ileitis occurs when severe colonic disease causes incompetence of the ileocaecal valve, leading to retrograde flow of colonic contents into the terminal ileum, with resulting inflammation. It occurs in up to $15 \%$ of UC colectomy specimens (Table $1 \& 2$ ).

Table 1: Classic diagnostic features of Ulcerative Colitis and Crohn's disease.

\begin{tabular}{|c|c|c|}
\hline Feature & Ulcerative Colitis & Crohn's Disease \\
\hline Disease distribution & Diffuse and continuous & Segmental \\
\hline Rectal involvement & Always (adults) & Occasionally \\
\hline Disease severity & Superficial (mucosal) & Transmural \\
\hline Disease location in colonic wall & Rare, underneath ulcers & Any location \\
\hline Transmural lymphoid aggregates & Related to ruptured crypts & Not crypt related \\
\hline Granulomas & Rare, superficial in fulminant colitis & Absent \\
\hline Fissures & Ony location & Occasional ('backwash') \\
\hline Ileal involvement & Ont &
\end{tabular}


Table 2: Differential Diagnosis.

\begin{tabular}{|c|c|}
\hline Diagnosis & Histologic Features \\
\hline Crohn's Colitis & $\begin{array}{c}\text { Focal inflammation; submucosal involvement; granulomas; goblet cell } \\
\text { preservation; transmural inflammation; fissuring. }\end{array}$ \\
\hline Ulcerative Colitis & $\begin{array}{c}\text { Distortion of crypts; acute and chronic diffuse inflammatory cell infiltrate; } \\
\text { goblet cell depletion; crypt abscesses; lymphoid aggregates. }\end{array}$ \\
\hline Microscopic Colitis & $\begin{array}{c}\text { Chronic inflammatory infiltrate; increased intraepithelial lymphocytes } \\
\text { (lymphocytic colitis) and subepithelial collagen band (collagenous colitis). }\end{array}$ \\
\hline Ischemic Colitis & $\begin{array}{c}\text { Mucosal necrosis with ghost cells; congestion with red blood cells; } \\
\text { hemosiderin-laden macrophages and fibrosis (when disease is chronic) }\end{array}$ \\
\hline Infectious Colitis & $\begin{array}{c}\text { Crypt architecture is usually normal; edema, superficial neutrophilic } \\
\text { infiltrate, crypt abscesses. }\end{array}$ \\
\hline Amebic Colitis & $\begin{array}{c}\text { Similar to ulcerative colitis; amebae present in lamina propria or in flask- } \\
\text { shaped ulcers, identified by periodic acid-Schiff stain. }\end{array}$ \\
\hline Pseudo Embranous Colitis & $\begin{array}{r}\text { May resemble acute ischemic colitis; shows summit lesions of Fibrino } \\
\text { purulent exudates. }\end{array}$ \\
\hline
\end{tabular}

\section{Indeterminate Colitis}

In the 1970s, it was first appreciated that there was a cohort of patients undergoing colectomy or proctocolectomy for chronic inflammatory bowel disease (CIBD) in whom a diagnosis of classical Crohn's disease (CD) or ulcerative colitis (UC) (or even certain infectious diseases) was not possible In 1978, Price introduced the concept of indeterminate colitis to describe cases in which colonic resections had been undertaken for chronic inflammatory bowel disease (CIBD), but a definitive diagnosis of either of the classical types of CIBD, ulcerative colitis and Crohn's disease, was not possible. This was especially apposite in cases of acute fulminant disease of the colorectum. More recently, the term indeterminate colitis has been applied to biopsy material, when it has not been possible to differentiate between ulcerative colitis and Crohn's disease (Figure 1) (Tables 3-9).

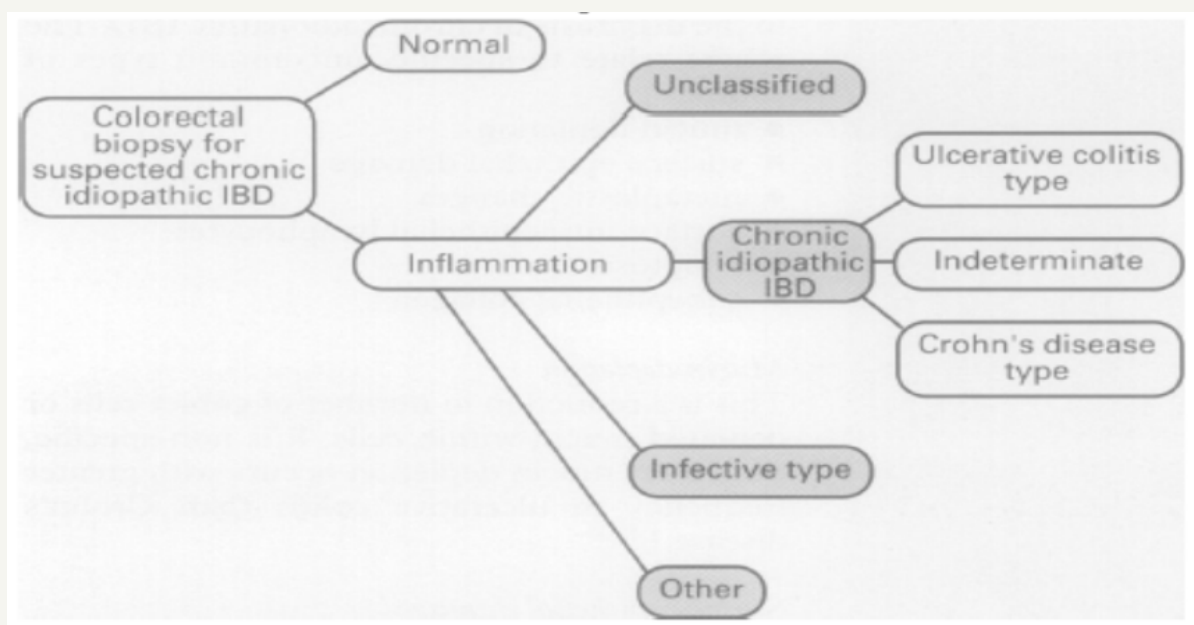

Figure 1: The diagnostic groups on which clinical decisions depend.

Table 3: Incidence of discriminating histological features in UC, CD, and IC*

\begin{tabular}{|c|c|c|c|c|c|}
\hline & IC & CD Urgent Surgery & Elective Surgery & UC Urgent Surgery & Elective Surgery \\
\hline Granulomas & 0 & 2 & 23 & 0 & 0 \\
\hline Fissures & 4 & 2 & 12 & 0 & 0 \\
\hline Typical CD & 18 & Not given & Not given & Not given & Not given \\
\hline V Shaped Defts & 28 & 2 & 30 & 20 & 0 \\
\hline $\begin{array}{c}\text { Transmural } \\
\text { Inflammation }\end{array}$ & & & & \\
\hline
\end{tabular}




\begin{tabular}{|c|c|c|c|c|c|}
\hline $\begin{array}{c}\text { Normal Goblet Cells, } \\
\text { Regular Gland Pattern, } \\
\text { and Focal Mucosal } \\
\text { Inflammation }\end{array}$ & 20 & 2 & 27 & 5 & 2 \\
\hline $\begin{array}{c}\text { Goblet Cell } \\
\text { Depletion, Glandular } \\
\text { Irregularity, } \pm \text { Diffuse } \\
\text { Mucosal Inflammation }\end{array}$ & 10 & 0 & 3 & 25 & 28 \\
\hline $\begin{array}{c}\text { Feature Suggestive of } \\
\text { Acute Disease } \pm \text { Dilation } \\
\text { Myocytosis and } \\
\text { Capillary Congestion }\end{array}$ & 21 & 0 & 0 & 22 & 0 \\
\hline V Shaped Defts & 18 & 0 & 0 & 6 & 0 \\
\hline
\end{tabular}

${ }^{*}$ Modified from Price.

CD: Crohn's Disease; ID: Indeterminate Colitis; UC: Ulcerative Colitis

Table 4: Frequency of detection of the reproducible features of each diagnosis.

\begin{tabular}{|c|c|c|c|c|c|c|}
\hline \multicolumn{7}{|c|}{ Frequency of Detection $\%$} \\
\hline Feature & Normal & Infective & $\begin{array}{c}\text { Chronic } \\
\text { Idiopathic IBD }\end{array}$ & $\begin{array}{l}\text { Ulcerative } \\
\text { Colitis }\end{array}$ & $\begin{array}{l}\text { Crohn's } \\
\text { Disease }\end{array}$ & Study \\
\hline \multicolumn{7}{|c|}{ Architecture } \\
\hline $\begin{array}{r}\text { Surface } \\
\text { irregularity }\end{array}$ & $0-5$ & $0-7$ & & 63 & 24 & 4,5 \\
\hline Villous surface & $0-6$ & & 39 & 30 & 12 & 2,7 \\
\hline $\begin{array}{l}\text { Villous surface } \\
\text { (v: } \mathrm{cr}>1.5: 1)\end{array}$ & 0 & & & 17 & 0 & 4 \\
\hline $\begin{array}{l}\text { Crypt numbers } \\
(<6 / \mathrm{mm})\end{array}$ & 10 & 0 & 95 & & & 5 \\
\hline $\begin{array}{l}\text { Branched } \\
\text { crypts }\end{array}$ & $0-5$ & & 75 & $63-83$ & $39-67$ & 4,7 \\
\hline $\begin{array}{l}\text { Crypt atrophy } \\
\text { (shortening) }\end{array}$ & $0-5$ & 0 & & $29-78$ & $12-37$ & $1,2,7$ \\
\hline $\begin{array}{c}\text { Abnormal } \\
\text { crypt architecture }\end{array}$ & $0-11$ & $0-30$ & $49-66$ & $57-100$ & $27-71$ & $1,2,3,6,7$ \\
\hline \multicolumn{7}{|c|}{ Chronic Inflammation } \\
\hline $\begin{array}{l}\text { Increased LP } \\
\text { cellularity }\end{array}$ & $0-19$ & 30 & $89-93$ & $76-92$ & $72-81$ & $3,4,6$ \\
\hline $\begin{array}{r}\text { Superficial: } \\
\text { basal }(<1.16: 1)^{*}\end{array}$ & 0 & 5 & 95 & & & $5,4,6$ \\
\hline $\begin{array}{c}\text { Increased } \\
\text { basal cellularity }\end{array}$ & 0 & 0 & & 63 & 62 & 4,5 \\
\hline $\begin{array}{r}\text { Basal } \\
\text { lymphoid } \\
\text { aggregates }\end{array}$ & & 0 & & 21 & 12 & 2 \\
\hline $\begin{array}{l}\text { Basal giant } \\
\text { cells }\end{array}$ & & $0-2$ & $13-16$ & 11 & 12 & 2,3 \\
\hline Granulomas & 0 & $0-2$ & $25-27$ & $0-5$ & $21-100$ & $1-4,6,7$ \\
\hline $\begin{array}{l}\text { Discontinuous } \\
\text { inflammation }\end{array}$ & 7 & & & 10 & 26 & 7 \\
\hline \multicolumn{7}{|c|}{ Acute Inflammation } \\
\hline $\begin{array}{c}\text { Crypt } \\
\text { intraepithelial } \\
\text { polymorphs }\end{array}$ & 0 & & 80 & $64-86$ & $48-75$ & 4,6 \\
\hline 1-10 NP/crypt & 4 & 39 & 47 & & & 5 \\
\hline$>10 \mathrm{NP} / \mathrm{crypt}$ & 0 & 0 & 18 & & & 5 \\
\hline $\begin{array}{r}\text { Crypt } \\
\text { abscesses }\end{array}$ & & & & 41 & 19 & 6 \\
\hline
\end{tabular}




\begin{tabular}{|c|c|c|c|c|c|c|}
\hline $\begin{array}{l}\text { Abscesses- } \\
\text { distensive }\end{array}$ & 1 & & & 18 & 32 & 7 \\
\hline $\begin{array}{l}\text { Abscesses- } \\
\text { disruptive }\end{array}$ & 0 & & & 14 & 26 & 7 \\
\hline $\begin{array}{c}\text { Crypt } \\
\text { neutrophilia }\end{array}$ & $0-2$ & & & 53-86 & $56-75$ & 4,7 \\
\hline $\begin{array}{l}\text { 1-10NP/Crypt } \\
\text { lumen }\end{array}$ & 0 & 17 & 17 & & & 5 \\
\hline $\begin{array}{l}>10 \mathrm{NP} / \text { Crypt } \\
\text { lumen }\end{array}$ & 0 & 0 & 7 & & & 5 \\
\hline $\begin{array}{l}\text { LP polymorphs } \\
\text { Increased }\end{array}$ & 6 & 14 & 59 & $61-63$ & $55-61$ & $2,6,7$ \\
\hline $\begin{array}{l}10-100 \mathrm{NP} / \\
\mathrm{mm} \mathrm{LP}\end{array}$ & 43 & 72 & 45 & & & 5 \\
\hline $\begin{array}{l}\text { 100-1000NP/ } \\
\text { mm LP }\end{array}$ & 0 & 17 & 48 & & & 5 \\
\hline $\begin{array}{l}>1000 \mathrm{NP} / \\
\mathrm{mm} \mathrm{LP}\end{array}$ & 0 & 0 & 6 & & & 5 \\
\hline \multicolumn{7}{|l|}{ Epithelium } \\
\hline $\begin{array}{l}\text { Surface } \\
\text { erosions }\end{array}$ & & $0-9$ & $24-29$ & 37 & 8 & 2 \\
\hline $\begin{array}{l}\text { Mucin } \\
\text { depletion }\end{array}$ & 17 & & & $35-69$ & $5-57$ & $1,6,7$ \\
\hline
\end{tabular}

Table 5: Major Diagnostic Criteria for CD.

Abdominal pain, diarrhea, and weight loss

Macroscopic features endoscopy such as aphthous erosions. skip lesions and cobblestone appearance

Radiologic evidence of intestinal stenosis, fistulae, and segmental colitis

Histologic evidence of transmural flogosis or presence of giant-cell epithelioid granuloma

Table 6: Major Diagnostic Criteria for UC.

\begin{tabular}{|c|}
\hline Diarrhea with a without blood and/or mucus in the feces \\
\hline Chronic flogosis of the colon, starting from the rectum \\
\hline Histologic features typical of UC \\
\hline
\end{tabular}

Table 7: Major Diagnostic Criteria for IC.

\begin{tabular}{|c|}
\hline Abdominal pain, bleeding diarrhea, and weight loss \\
\hline Endoscopic macroscopic features of erosions and ulcers of the colon \\
\hline Pancolitis with "rectal sparing" \\
\hline Early onset \\
\hline Diffuse, transmucosal lamina propria cell increase and patchy inflammation \\
\hline
\end{tabular}

\section{Table 8.}

Morphological macroscopic features seen in indeterminate colitis

$$
\text { Extensive ulceration }
$$

Involvement of transverse and right colon (more severely than distal colon)

Involvement of $>50 \%$ of the mucosal surface

Toxic dilation may be present

Table 9.

\begin{tabular}{|c|c|c|}
\hline Morphological Macroscopic Features Seen in Indeterminate Colitis \\
\hline Extensive ulceration \\
\hline Involvement of transverse and right colon (more severely than distal colon) \\
\hline Involvement of $>50 \%$ of the mucosal surface \\
\hline
\end{tabular}




\begin{tabular}{|c|}
\hline Usually diffuse disease, but may show rectal sparing \\
\hline Toxic dilation may be present \\
\hline Morphological Microscopic Features Seen in Indeterminate Colitis \\
\hline Extensive ulceration with a sharp transition to normal adjacent mucosa. \\
\hline Transmural lymphoid inflammation, with an absence of lymphoid aggregates. \\
\hline Absence of well-defined, epithelioid granulomas distant from crypts. \\
\hline Multiple squat V-shaped ulcers, lacking surrounding inflammation. \\
\hline $\begin{array}{c}\text { Scanty deep penetrating slit-like fissures, described more recently by some authors as 'knife-like', spreading into the superficial half of the muscularis } \\
\text { propria. }\end{array}$ \\
\hline
\end{tabular}

Common Reasons for Making a Diagnosis of Indeterminate Colitis

A. Fulminant colitis (fissures, transmural inflammation, rectal sparing in UC)

B. Insufficient clinical, radiologic, pathologic information

C. Interpretation of mucosal biopsy specimen

D. Failure to recognize unusual variants of UC and CD UC with Relative rectal sparing Superficial fissure Granulomas related to ruptured crypts Right sided involvement in left sided colitis Appendiceal involvement Backwash ileitis Therapy effect $\mathrm{CD}$ with diffuse mucosal involvement

E. Failure to utilize hard criteria for CD Transmural inflammation Granulomas Deep fissuring ulceration Ileal involvement Segmental disease

F. Presence of secondary disease (for example, pseudomembranous colitis, ischemic colitis, infection)

\section{Diagnostic Approach to IBD}

The diagnostic process should be standardized for better practice [15]

A. When UC is suspected clinically, the recommended stepwise diagnostic approach is the following.

B. Routine fecal examinations and cultures should be carried out to rule out diseases such as bacillary dysentery, amoebiasis, schistosomiasis etc.

C. Colonoscopic examination and biopsy should be done, except for patients with fulminant disease.

D. Barium enema should be performed if necessary.

E. Routine laboratory examinations such as the complete blood count (CBC), plasma protein, erythrocyte sedimentation rate (ESR), and C-reactive protein (CRP) tests are helpful. Plain radiology, blood electrolytes and culture might be necessary for severe cases.

F. Endoscopic proctitis (or cryptogenic colitis) cannot be diagnosed as UC and cannot be used as a clinical diagnosis.

G. When CD is suspected clinically, the recommended stepwise diagnostic approach is the following (once TB infection has been excluded by relevant examinations, such as chest X-ray, old tuberculin test and serum purified protein derivative antibody test.
H. Endoscopy, contrast GI examination, or videocapsule endoscopy should be done according to the possible involved segments.

I. Computed tomography or ultrasonography might be needed for involved bowel wall and extra-intestinal complications.

J. Laboratory examinations as used in UC for activity and severity assessment of the disease. Biopsy from involved area for pathological figures and AFB, and TB DNA analysis on TB and CD tissues with TB special primers if possible.

\section{Further Directions for Diagnosis of IBD}

There is a need to implement objective diagnostic criteria for UC and CD in the Asia-Pacific region. This is essential to minimize confusion and misdiagnosis, which arise in studies on epidemiology as well as in studies elucidating etiopathogenesis. The differential criteria between intestinal tuberculosis and CD are particularly important because TB is still rampant in this region and the incidence of $\mathrm{CD}$ is also on the rise in this region. The diagnostic markers from serum, feces and tissue will be helpful for the diagnosis of IBD and for differential diagnosis. Evolution of genetic assays as diagnostic tools should be one of the forward leaps in this area.

\section{Recommendations}

A. Restrict the term 'indeterminate colitis' to CIBD pathological features present at colectomy (macroscopically and microscopically).

B. Remember that 'indeterminate colitis' is a temporary term, to be used until a diagnosis of either UC or CD is established.

C. Never label biopsy cases as 'indeterminate colitis'. These should be classified as 'equivocal CIBD', 'nonspecific CIBD', 'unclassified CIBD' or 'inflammatory bowel disease, type unclassified' (IBDU).

D. Refrain from subclassifying IC, as this further complicates matters and can mislead clinicians. Do not deny IC patients reconstructive surgery such as pouch surgery, as the overall failure rate is similar to that of $\mathrm{UC}$, but careful preoperative assessment to exclude CD is essential.

E. Await further research, particularly genetic and molecular analysis, to enable better differentiation of CD from UC and ultimately (hopefully) abrogate the need for the term 'indeterminate colitis'. 


\section{Conclusion}

Ultimately, we recognize that clinically, endoscopically and pathologically, colorectal CIBD represents a spectrum of disease with classical UC and CD at either ends of that spectrum. What we recognize as IC in colectomy specimens and IBDU (or equivocal/nonspecific CIBD) in colorectal biopsies both lie in the middle ground but are certainly not the same disease. Whilst advances in serological assays and in molecular and genetic biology show some promise and may assist in the clarification of the type of CIBD in individual cases, it may be that these technologies reinforce the concept of this spectrum and that we shall continue to encounter CIBD cases with equivocal features. It seems that pathologists are reluctant to make a diagnosis of IC, perhaps because they perceive that such a diagnosis may be interpreted as an indicator of their own diagnostic uncertainty. In the second opinion practice of one of the authors (N.A.S.), IC is often the diagnosis ultimately made, as even 'expert' gastrointestinal pathologists cannot necessarily differentiate between UC and CD in fulminant colitis cases.

It must be emphasized, therefore, that IC may be an entirely appropriate diagnosis and should not be perceived as a reflection of the quality of the pathological assessment. Pathologists must accept that diagnostic equivocation may well be appropriate and there is now sufficient evidence, from the literature, to guide pathologist, surgeon and patient to the relevant management in the majority of cases of acute fulminant CIBD.

\section{References}

1. Kent TH, Ammon RK, Den Besten L (1970) Differentiation of Ulcerative Colitis and regional enteritis. Arch Pathol 89(1): 20-29.

2. Yantiss RK, Odze RD (2007) Pitfalls in the interpretation of nonneoplastic mucosal biopsies in inflammatory bowel disease. Am J Gastroenterol 102(4): 890-904.

3. Garcia OS, Takahashi T, Gamboa DA, Medina H, Arch J, et al. (2000) Toxic pseudomembranous colitis in a patient with ulcerative colitis. Inflamm Bowel Dis 6(3): 188-190.
4. Prantera C, Lochs H, Campieri M, Scribano ML, Sturniolo GC, et al. (2006) Antibiotic treatment of Crohn's disease: Results of a multicentre, double blind, randomized, placebo-controlled trial with rifaximin. Aliment Pharmacol Ther 23(8): 1117-1125.

5. Geboes K, Van Eyken P (2009) Inflammatory bowel disease unclassified and indeterminate colitis: the role of the pathologist. J Clin Pathol 62(3): 201-205.

6. Geboes K (2001) Pathology of inflammatory bowel disease (IBD): variability with time and treatment. Colorectal Dis 3(1): 2-12.

7. Shepherd NA (2002) Granulomas in the diagnosis of intestinal Crohn's disease: a myth exploded? Histopathology 41(2): 166-168.

8. Cuvelier C, Demetter P, Mielants H, Veys EM, De Vos M, et al. (2001) Interpretation of ileal biopsies: morphological features in normal and diseased mucosa. Histopathology 38(1): 1-12.

9. Odze R (2003) Diagnostic problems and advances in inflammatory bowel disease. Mod Pathol 16(4): 347-358.

10. Rudolph WG, Uthoff SMS, McAuliffe TL, Goode ET, Petras RE, et al. (2002) Indeterminate colitis. The real story. Dis Colon Rectum 45(11): 15281534 .

11.Day DW, Jass JR, Price AB (2003) Inflammatory disorders of the large intestine. In: Day DW, et al. (Eds.), Morson and Dawson's gastrointestinal pathology, ( $4^{\text {th }}$ edn), Blackwell Science, Oxford, USA, pp. 472-539.

12.Yantiss RK, Odze RD (2006) Diagnostic difficulties in inflammatory bowel disease pathology. Histopathology 48(2): 116-132.

13. Robert ME, Tang L, Hao LM, Reyes MM (2004) Patterns of inflammation in mucosal biopsies of ulcerative colitis: perceived differences in pediatric populations are limited to children younger than 10 years. Am J Surg Pathol 28(2): 183-189.

14.Mutinga ML, Odze RD, Wang HH, Hornick JL, Farraye FA (2004) The clinical significance of right-sided colonic inflammation in patients with left-sided chronic ulcerative colitis. Inflamm Bowel Dis 10: 215-219.

15. Chinese Society of Gastroenterology (2001) Suggested guideline for the diagnosis and treatment of inflammatory bowel disease. Chin J Dig Dis 2(4): 202-208.
Creative Commons Attribution 4.0 International License

For possible submissions Click Here

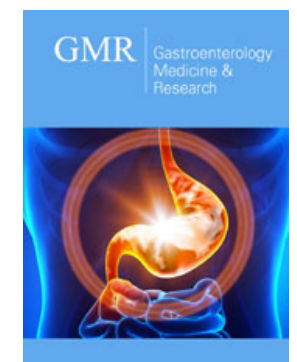

\section{Gastroenterology Medicine \& Research}

\section{Benefits of Publishing with us}

- High-level peer review and editorial services

- Freely accessible online immediately upon publication

- Authors retain the copyright to their work

- Licensing it under a Creative Commons license

- Visibility through different online platforms 